\title{
La pornografía en el programa critico
}

The pornography by the critical program

\author{
Xabier InSAUSTi \\ Universidad del País Vasco \\ xabier.insausti@ehu.eus
}

DOI: http://doi.org/10.15366/bp2019.21.007

Bajo Palabra. II Época. No21. Pgs: 127-144 
Xabier Insausti Ugarriza es doctor en Filosofía por la Ludwig-Maximilians-Universität de Múnich (Alemania). Cofundador de la Red Internacional de Pensamiento Crítico.

En la actualidad es profesor de Teoría del Conocimiento en la Universidad del País Vasco.

Ha publicado diversos trabajos sobre el Idealismo Alemán, especialmente sobre Hegel. En

Plaza y Valdés ha editado las obras colectivas Pensar la filosofía hoy (2011) y

Filosofía e inmanencia (2015). Ha traducido al euskera la Phänomenologie des Geistes

(Fenomenología del espiritu) de Hegel, además de otros libros de Adorno y Freud.

\section{नiverays}

\section{Resumen}

Susan Sontag escribió un polémico artículo sobre la pornografía: "The pornographic Imagination" en el que hace una referencia a Hegel. Hegel cambia radicalmente el modo de entender el quehacer filosófico y así inaugura, a su entender, un nuevo lenguaje post-religioso que abre posibilidades hasta entonces desconocidas a la cultura occidental. El concepto de negatividad es central. La pornografía es un ejercicio radical de negatividad. El sujeto recorre un camino de aprendizaje doloroso pero necesario para llegar a su liberación. Por esta vía "crítica" van a discurrir autores como Freud, Sartre, Derrida o Genet que presentamos brevemente en este artículo de la mano de Sontag.

Palabras Clave: Hegel, post-religión, post-pornografia, Susan Sontag, programa crítico.

\section{Abstract}

Susan Sontag wrote a controversial article about pornography: "The pornographic Imagination" in which she refers to Hegel. Hegel radically changes the way of understanding the philosophical task and thus inaugurates, in her understanding, a new post-religious language that opens possibilities hitherto unknown to Western culture. The concept of negativity is central. Pornography is a radical exercise in negativity. The subject travels a painful but necessary learning path to reach their liberation. In this "critical" way, authors such as Freud, Sartre, Derrida or Genet are presents briefly in this article coming from the hand of Sontag.

Keywords: Hegel, post-religion, post-pornography, Susan Sontag, critical program. 
En el interesante artículo de Susan Sontag "The Pornographic Imagination" (en: Susan Sontag, Against Interpretation, 1962) encontramos una sorprendente referencia a Hegel: "Hegel made perhaps the grandest attempt to create a post-religious vocabulary, out of philosophy, that would command the treasures of passion and credibility and emotive appropriateness that were gathered into the religious vocabulary. But his most interesting followers steadily undermined the abstract meta-religious language in which he had bequeathed his thought, and concentrated instead on the specific social and practical applications of his revolutionary form of process-thinking, historicism. Hegel's failure lies like a gigantic disturbing hulk across the intellectual landscape. And no one has been big enough, pompous enough, or energetic enough since Hegel to attempt the task again". Recurrir a Hegel (aunque sólo sea someramente) en un artículo dedicado a reflexionar sobre pornografía y literatura resulta al menos extraño y sorprende sobremanera. ¿Qué tiene que ver Hegel con la pornografía?

La idea básica es que Hegel le dio a la filosofía una impronta especial, un cambio de rumbo fundamental, un lenguaje radicalmente nuevo. Hegel revolucionó la filosofía de un modo especial equiparable quizás sólo al realizado por Nietzsche. Incluso más radical que el de Nietzsche, por cuanto hocea directamente en sus predecesores como Kant, que es la "Ilustración europea" al decir de Horkheimer. Kant es el punto de partida, el último eslabón de la vieja filosofía, el que consolida el suelo por el que va a transitar irremediablemente la filosofía posterior. En definitiva, el que hace posible la filosofía alemana, en definitiva, la filosofía. Sin Kant no hay Hegel. Y Hegel es toda la filosofía, como Beethoven es toda la música, como decía Adorno. Hegel arrebató el lenguaje filosófico a la academia que lo tenía secuestrado y se lo entregó a los humanos. Como Hegel mismo decía al comienzo del llamado Differenzschrift, se trataba de volver a reunir la filosofía (que se había perdido en elucubraciones abstractas) y la vida (que había perdido la conexión con la filosofía). La operación realizada por Hegel es revolucionaria en un sentido literal. La conciencia "natural" se va a ir transformando progresivamente, a lo largo del viaje "fenomenológico", en la conciencia "invertida", "desventurada", "ética", "moral", "religiosa" hasta llegar a una nueva tierra prometida que Hegel llama conciencia "absoluta" a partir de la cual la "vida" adquiere una dimensión radicalmente nueva, "postreligiosa", incluso podríamos denominarla "postfilosófica". Se trata nada 
menos que de poner de nuevo a la "vida" en el centro de atención, de recuperar la "vida" concreta de los seres humanos como el objeto central de la filosofía. Die Phänomenologie des Geistes es la guía de dicho camino desde la "conciencia natural" hasta la verdadera filosofía, hasta la vida misma.

En otro artículo recogido en el citado libro, Sontag reflexiona sobre la operación realizada por Sartre sobre Genet en el libro Saint Genet, Comédian et Martyr (1952). Sontag desarrolla la idea de que Sartre entiende a Genet fundamentalmente como a un hegeliano que recorre, aun sin saberlo, las figuras fundamentales que Hegel despliega en la Phänomenologie en un esfuerzo radical de realización de uno mismo (Selbst). Genet, en su quehacer literario y en su vida personal (que serían lo mismo), sigue con fidelidad radical la "astucia" de una razón que le guía, la misma que le llevó a Ulises hasta Ítaca. Y algo parecido ocurre con el Genet de Derrida en Glas. Que Derrida sitúe a Genet en directa confrontación, página a página, con Hegel nos obliga a repetir y repensar el ejercicio sartriano, aunque sea en una clave distinta.

La segunda lección que extraemos de la cita de Sontag es que ni los mismos seguidores de Hegel fueron capaces de comprender la radicalidad del planteamiento hegeliano. Se cayó, tras su desaparición, en un historicismo nivelador e insulso. Esta idea de la incapacidad de los mismos hegelianos de entender a su maestro ha sido subrayada por muchos autores: Gadamer: tenemos que volver a leer al pie de la letra ("buchstabieren"), es decir sin prejuicios, a Hegel (Gadamer: Hegels Dialektik, Verlag J.C.B. Mohr, Paul Siebeck, Tübingen, 2. vermehrte Auflage, 1980); Adorno (Drei Studien zu Hegel, Suhrkamp, Frankfurt/M. 1971), Henrich (el que quiere entender hoy a Hegel se encuentra sólo, de nada sirve toda la gigantesca literatura sobre el filósofo; Henrich, Hegel im Kontext. Suhrkamp, Frankfurt/M. 1971, 7), Zizek (debemos volver a fundar las bases teóricas de la filosofía. Zizek, Less than Nothing, Verso, London/New York, 2012). El hecho de que Hegel se nos haya hecho tan difícil de comprender, no es un problema para Hegel, sino para nosotros; no hay que escribir de nuevo a Hegel para que podamos entenderlo hoy, más bien se trata de aprender a leerlo. Estamos huérfanos porque hemos matado al padre alguien habló de "un perro muerto" refiriéndose a Hegel - en todo caso no hemos sabido qué hacer con su herencia más allá del gesto salvaje del depredador egoísta que busca carroña a cualquier precio.

Hegel es mucho más que otro filósofo más. Parafraseando a Adorno, como hemos dicho, así como Beethoven fue toda la música, toda la historia de la música, asimismo Hegel fue toda la filosofía. Hegel digiere toda la herencia cultural europea y la abre a una nueva dimensión, un nuevo horizonte sin vuelta atrás. Tras él, sólo se puede partir de él. "Realiza" a la filosofía. Hegel es un filósofo que se propuso elevar 
(o bajar) el lenguaje filosófico (atrapado en el imaginario religioso)" explicando" su contenido. La historia le castigó con el olvido. Pero la verdad rechazada se venga obligando a los humanos a repetir lo que ya parecía superado. Por ello no podemos entender a Marx; porque sólo se entiende desde Hegel. Aunque algunos pretendían inútilmente que Marx había dejado atrás a Hegel, lo había "superado" y que por ello podíamos olvidarlo.

\section{II}

Pero iQué Quiere Decir un leguaje post-Religioso? Lo que Hegel nos enseñó es a leer la "historia", a preguntarnos para qué sirve la historia (antes que Nietzsche). Nos enseñó a releer fundamentalmente a los griegos, a la tragedia griega, pero también a Platón y Aristóteles. Y nos enseñó, a releer la historia medieval y moderna, una historia que aparecía con una gruesa pátina religiosa tras la cual se escondían potencialidades enormes a la espera de ser rescatadas. Hegel nos ensenó que es posible y necesario buscar un nuevo lenguaje capaz de "expresar" los contenidos ocultos y reconducirlos a lo que en definitiva son: momentos de la "vida" misma. Hegel encontró el lenguaje adecuado que devolviera los contenidos religiosos a su origen mismo que es la vida. Y, así, dio la clave para hacer lo mismo con todo otro contenido, bien sea artístico, político, científico .... o pornográfico. Lo mismo puede valer para otros contenidos, también para el reencuentro de la pornografía y la vida. Que la religión se halla al servicio de la vida y no al revés, es la gran lección de Hegel. Lo mismo que la ciencia. La crisis de las ciencias, que más tarde anunciara Husserl en La crisis de las ciencias europeas, ya la anticipó Hegel. Pero en el tiempo de Hegel era la religión la que se hallaba en concurrencia por tratar de usurpar el lugar que le corresponde sólo a la vida. En este sentido, Hegel desarrolla un lenguaje post-religioso, capaz de devolver a la vida su lugar. Así lo anuncia al comienzo del llamado Differenzschrift. Ahora se trataba de desarrollar ese nuevo lenguaje en un sistema filosófico adecuado. Es su trabajo durante los años de Jena.

En este sentido, la tarea que hemos heredado de Hegel es desarrollar la idea básica de que la filosofía se halla al servicio de la vida. A pesar de las diferencias, la operación fundamental que encontramos en Sartre, Derrida o Sontag es la misma: buscar un lenguaje para hablar de contenidos que, de otro modo, quedarían en las manos fraudulentas de los mercaderes que saben explotarlos sin escrúpulo, es decir, incluso contra la vida misma. $Y$ en este uso fraudulento de los contenidos reales de la vida se encuentran interesados tanto los mercaderes del templo, las iglesias, como 
los mercaderes capitalistas. Es preciso por tanto desenmascarar sus intereses ocultos y devolver así la pornografía al lugar que le corresponde, es decir, a la vida.

En definitiva, Hegel desarrolló un lenguaje capaz de expresar la riqueza del imaginario religioso, tan rico en metáforas, sugestiones, propuestas. El mundo barroco del que viene directamente la cultura europea (como explicó Benjamin) es un mundo cargado de vida, cargado de motivos humanos, un rico mundo cargado de pasión, de formas, de colorido, el mundo que hay que salvar y mantener. Para ese mundo necesitamos un lenguaje adecuado. El Bosco en El jardín de las Delicias ha encontrado un lenguaje pictórico. En el panel central aparece un mundo feliz de seres disfrutando, sin preocupación, de los placeres de la vida. Evidentemente, el infierno no puede faltar porque aún estamos inmersos en un imaginario fuertemente atrapado en su época. En su lenguaje barroco El Bosco encuentra la manera de representar todos los registros de un mundo cargado de vida, pero ordenado según los parámetros de su época, un mundo en el que no falta ninguno de los registros de los placeres mundanos. Su obra es una auténtica fenomenología de la vida.

El Verbo se hizo carne con Hegel (y luego con Freud, podemos añadir). Hegel habría robado el fuego divino y se lo habría entregado a los humanos. Del imaginario religioso, de su inmensa riqueza es de donde brota la cultura europea, pero ahora va a ser a la medida del ser humano. Por ello será la Historia la que ocupe el lugar del primer y del tercer panel de El Bosco. La Historia marca el desarrollo de la vida. El surgimiento (nacimiento) y el fin (la muerte) van a ser ahora los dos extremos entre los que se desarrolla la vida, el panel central.

\section{III}

SONTAG DiCE, CON RAZÓN, que Hegel puso en marcha "perhaps the grandest attemp to create a post-religious vocabulary" (ver cita al comienzo de este artículo). Esta frase cobra todo su sentido si la situamos en la perspectiva de la filosofía de Fichte, especialmente del llamado último Fichte. En esta última época (1810-1814), Fichte orienta su reflexión hacia la "vida" entendida en clave religiosa. Esto ocurre en su obra en torno a 1800 y especialmente de 1810 hasta su muerte en 1814. Fichte busca profundizar en su propia filosofía, poniendo en el centro de su reflexión el mensaje teológico de Juan el Evangelista, en que Fichte vio la más pura expresión del cristianismo y una profunda coincidencia con su especulación filosófica. Fichte estaría buscando un "resumen" de sus posiciones anteriores, un centro inequívoco y claro, hasta entonces no alcanzado, desde el que, en la simplicidad de una única 
mirada suprema totalizadora, dominar todo el ámbito de su filosofía, de la Doctrina de la Ciencia. Así lo expresa el filósofo alavés José Manzana: "Se tiene la impresión de que en las últimas exposiciones de la Doctrina de la Ciencia se alcanza una posición suprema en que el dinamismo de la energía especulativa ascensional se remansa soberanamente y domina 'desde arriba' todos los momentos subjetivos y materiales de la existencia humana" (Manzana: Obras Completas, 3. Volumen. Ed. por Aguirre/Insausti, ed. Scriptorium Victoriense 2019. Que sea precisamente el "amor" ese elemento-bisagra último de cierre de la filosofía, abre una perspectiva a la filosofía postkantiana hasta ahora desconocida, la posibilidad de un planteamiento nuevo.

Hegel seguirá otro camino, pues declara su alejamiento de Fichte ya en su primera obra publicada, el llamado Differenzschrift (Escrito de la diferencia), escrita ya en Jena. En su época de Jena (1801-1807) Hegel busca un camino nuevo para la filosofía, que le llevará hasta la Phänomenologie des Geistes (Fenomenología del Espíritu), una obra que en principio no tenía otra pretensión que ser introducción al sistema, pero en el proceso de elaboración se fue creciendo hasta llegar s ser una obra independiente y original, la obra más expresionista de Hegel.

Podríamos resumir diciendo que mientras Fichte se habría quedado atrapado en un lenguaje "religioso", como se puede interpretar la tercera época de su filosofía, Hegel va más allá. Hegel, tras un largo e intensivo esfuerzo, va a encontrar hacia el final de sus ańos de Jena dentro de la filosofía misma su propio camino. Para ello desarrollará una lógica propia, base de todo su proyecto filosófico. Englobará a todos los otros ámbitos, también al religioso, que quedará amarrado al "sistema" filosófico. Será por tanto una filosofía estrictamente post-religiosa. Quizás el problema sea que aún no hemos llegado a Hegel, como insinúa Sontag.

\section{IV}

Sontag define la pornografía de un modo no convencional: "She - dice Siri Hustvedt en un artículo titulado "Siri Hustvedt about Susan Sontag", - Sontag, emphasizes that her adjective "classical" for pornography is something of a joke and that her definition of porn is unconventional: as a literary form it must embody the idea that lustful acts are inherently immoral" [Nota: A special project for $92 Y$ Unterberg Poetry Center's 75th anniversary, 75 at 75 invites authors to listen to a recording from our archive and write a personal response. Here, Siri Hustvedt writes about Susan Sontag's lecture "On Classical Pornography." It was recorded live at $92 Y$ on November 2, 1964. Posted on Mar 6, 2014] (leida en la web). 
Para Sonntag la pornografía que ella misma analiza «es una forma literaria que debe incorporar o actuar en contra de la idea según la cual los actos lujuriosos son intrínsecamente inmorales" ("ords of art which embody, reflect, react to or against the idea that lascivious or lustful thoughts or acts are inherently immoral", "The Pornographic Imagination"). Y advierte de la cercanía entre lo religioso y lo pornográfico. En las obras que ella analiza (Sade, Bataille, Histoire d'O y otros), obras con un valor realmente literario a su entender, hay un elemento fundamental que va ligado necesariamente a la pornografía, que es la muerte, la negación absoluta. La muerte, dice, es la esencia de la pornografía. Lo que busca la pornografía es comprender la muerte, buscarla, experimentarla, hacerla propia. "One reason that Histoire de l'oeil and Madame Edwarda make such a strong and unsettling impression is that Bataille understood more clearly than any other writer I know of that what pornography is really about, ultimately, isn't sex but death. I am not suggesting that every pornographic work speaks, either overtly or covertly, of death. Only works dealing with that specific and sharpest inflection of the themes of lust, "the obscene," do. It's toward the gratifications of death, succeeding and surpassing those of Eros, that every truly obscene quest tends." (p. 60).

La muerte está presente como algo substancial en lo pornográfico. ¿Por qué? Lo pornográfico conlleva un elemento de negación, de disolución del yo, un instinto de muerte que es substancial al ser humano, como dejó claro Freud. Esta atracción es necesaria para poder articular dialécticamente la doble cara de la vida. La Histoire $d^{\prime} O$ es interpretada por Sontag como la historia de una mujer que se entrega "al mismo tiempo a su disolución como ser humano y a su realización como ser sexuado" ("gleichzeitig auf ihre Auslöschung als menschliches Wesen und ihre Erfüllung als geschlechtliches Wesen" (p. 7 de la ed. alemana). En Histoire d'O leemos: "Por este medio [se refiere a los latigazos que recibe la protagonista], al igual que por el de la cadena que, sujeta a la anilla del collar, te mantendrá amarrada a la cama varias horas al día, no se trata de hacerte sentir dolor, gritar ni derramar lágrimas, sino, a través de este dolor, recordarte que estás sometida a algo que está fuera de ti." ¿Qué es este poder fuera del ser humano al que el ser humano debe someterse para realizarse como ser sexuado? En una entrevista publicada en Die Zeit (Nr. 18 vom 23. April 1976) dice Sontag explicando esta aparente contradicción (realizarse por medio de la disolución) en La Histoire d'O: 'Mein Interesse an dem Buch beruhte und beruht noch immer auf dem Freimut, mit dem es sich der dämonischen Seite der sexuellen Phantasie annimmt. Die grausame Unbedingtheit der Phantasie, für die es Partei nimmt (und die es keineswegs beklagt), ist mit der optimistischen und rationalistischen Denkweise nicht zu vereinbaren, die im Feminismus vorherrscht. Das utopische Denken der Pornographie ist auf eine negative Utopie aus, wie die 
meiste Science-fiction-Literatur". "Mi interés en el libro se basaba y se basa todavía hoy en la franqueza con la que asume la parte demoniaca de la fantasía sexual. La incondicionalidad cruel de la fantasía por la que toma partido -y de la que no se queja-no es compatible con el modo de pensar optimista y racional que domina en el feminismo. El pensamiento utópico de la pornografía apunta a una utopía negativa como la de la literatura de ciencia-ficción".

$\mathrm{Y}$, tras esta crítica al optimismo racionalista dominante, a su entender, en el feminismo, continúa "Wie sich der Geschlechtstrieb im Menschen auswirkt, scheint mir etwas von Grund auf Fehlerhaftes oder Frustrierendes an sich zu haben. Es scheint, daß sich die volle Entwicklung unseres sexuellen Wesens nicht mit der vollen Entwicklung unseres Bewußtseins verträgt. Anstatt anzunehmen, daß alle unsere sexuelle Unzufriedenheit ein Teil des Preises dafür ist, den die Kultur der Sexualität abverlangt, ist es vielleicht richtiger, davon auszugehen, daß wir zunächst von Natur aus krank sind - und daß unser Status als "kranke Tiere", wie Nietzsche es nannte ["Denn der Mensch ist kränker, unsicherer, wechselnder, unfestgestellter als irgendein Tier sonst, daran ist kein Zweifel - er ist das kranke Tier: woher kommt das?", Zur Genealogie der Moral 13], uns erst zu Tieren macht, die Kultur hervorbringen. Dieser angeborene Widerspruch zwischen sexueller Erfüllung und individuellem Bewußtsein wird noch dadurch verschlimmert, daß in der modernen, verweltlichten Kultur die Sexualität eine größere Rolle spielt." ("El instinto sexual tal como funciona en el ser humano me parece conllevar en sí algo desde su raíz deficiente o frustrante. Parece que el desarrollo completo de nuestra esencia sexual no es compatible con el desarrollo completo de nuestra conciencia. En vez de suponer que toda la insatisfacción sexual nuestra es una parte del precio que exige la cultura de la sexualidad, quizás sea más correcto partir de que somos por naturaleza enfermos - y que nuestro estatuto como "seres enfermos", como lo llamó Nietzsche [ ¡El ser humano es más enfermo, más inseguro, más cambiante, menos constante que cualquier otro animal, de ello no hay ninguna duda él es $e l$ animal enfermo, ¿de dónde proviene esto?” Zur Genealogie der Moral 13], nos convierte en animales que producen la cultura. Esta contradicción innata entre la realización sexual y la conciencia individual se acentúa por el hecho de que en la cultura moderna, laica la sexualidad juega un papel muy importante").

En definitiva, Sontag entiende que se da una contradicción insuperable ("por naturaleza") que hace de los seres humanos "animales salvajes", animales que tratan de huir de su condición al precio de la ignorancia de su propia condición, lo cual les hace animales más peligrosos que los animales salvajes. Querer anular esta contradicción de un modo unilateral, es decir, cerrando los ojos violentamente a uno de los términos del binomio, sólo logra empeorar las cosas. 
La cultura occidental (especialmente la cultura de la conciencia) habría querido quedarse unilateralmente con la parte racional, teórica, abstracta, triunfalista, olvidando que existe otra poderosa potencia humana. Es la dialéctica de la ilustración que Adorno y Horkheimer pusieron de relieve precisamente en la obra que lleva ese mismo nombre: Dialéctica de la ilustración (1944). El ser humano ilustrado ha despreciado la naturaleza tanto externa como interna. Los autores frankfurtianos parecen más optimistas que Sontag o Nietzsche. Para ellos la clave está en saber articular ambos extremos de la dialéctica (vida y muerte). Y aquí es precisamente donde la cultura occidental habría fracasado. Husserl había apuntado, en los años 30, a la concepción de la ciencia moderna como culpable del fracaso de la cultura por cuanto habría olvidado que se halla al servicio de la vida y no al revés. Así, la ciencia moderna habría puesto la vida misma a su servicio obligándola a ésta última a seguir pautas ajenas a ella misma, como son las de la ciencia enajenada de su primigenio vínculo con la vida y funcionando de modo autónomo, autista. Ernst Bloch hablaba de una izquierda aristotélica presente desde el comienzo en la filosofía occidental que, como el Guadiana, aparece de vez en cuando (Maimónides, Averroes, Espinoza, Hegel), pero que habría sido arrinconada reprimida por otra.

Contra las filosofías triunfalistas idealistas impuestas en la Academia se hallan presentes estas otras filosofías materialistas que subrayan la otra parte olvidada, la sombra de la conciencia. Al cabo, Freud señalará que esta parte reprimida es la más fundamental, más básica, más primaria por cuanto está condicionando a la otra que sólo puede articularse desde ella. La otra sería, contra la interpretación oficial de la Academia ilustrada, la secundaria, la represora. Dirige por tanto la mirada, con razón, a la otra parte, la reprimida, la olvidada por la Academia. Freud, optimista ilustrado, trató de dominar al Ello desde el Yo, al menos hasta que la realidad (nazi) le enmendó la plana.

\section{$\mathrm{V}$}

Sartre y Derrida vuelven a Hegel y Genet para ilustrar una visión carnal, material, "real" del mundo. El libro de Sartre al que nos referimos se titula: Saint Genet, Comédian et Martyr (1952). El texto de Derrida lleva por título la enigmática palabra Glas (1974).

Sartre ve en Genet un héroe místico que celebra la eucaristía del misterio del mundo, de la naturaleza, de la redención humana. Genet es, en la lectura de Sartre, el Cristo actual. Su sufrimiento es el de quien no logra la perfección buscada, de quien ha cargado sobre sus espaldas el dolor del mundo y quiere redimirlo. Genet es 
un mártir del tiempo al que trata de redimir con su propio sacrificio, con su inmolación incondicional. Sartre, que había asistido a los cursos sobre Hegel de Kojève, realiza un paralelismo entre los pasos que Hegel desarrolla en la Phänomenologie y el decurso de la vida y obra de Genet.

En su monumental obra, Sartre incorpora (y así salva) a Genet al mundo filosófico occidental. Y, al revés, trata de salvar la filosofía haciéndola cómplice de la vida y obra de Genet. Sartre lee en Genet las figuras que Hegel recorre en la Phänomenologie, y éstas no son otra cosa que los hitos de la historia occidental. ¿Delirio sartriano o agudeza sin precedentes? ¿Dónde se encuentran Hegel y Genet?

Genet es para Sartre el artista total, mucho más que Baudelaire, al que dedicó unos ańos antes una obra (Baudelaire 1947), que puede considerarse antecesora directa de la dedicada a Genet. La diferencia entre ambos personajes es clara para Sartre: Genet, a diferencia de Baudelaire, se encuentra en el centro mismo de la cultura europea. El Verbo se hace carne en su obra y en su vida. Sartre y Genet eran buenos amigos (al menos hasta que Sartre escribió esta obra). Esto hace mucho más directa, casi obscena la relación entre ambos. El mismo Sartre parece querer hacerse uno con Genet, hacer suya su relación con el mundo que construye Genet. Este personaje encarna mi filosofía, parece querer decir Sartre. Sartre explica, desarrolla, crea filosóficamente lo que se halla tras las bambalinas literarias de Genet. Y ahí Sartre encuentra las figuras de la Phänomenologie des Geistes. Genet realiza el programa de Hegel. Los pasos que marca Hegel los realiza Genet. Genet no sólo no es un marginal, sino que ocupa un lugar central en la cultura europea. Genet "realiza" lo que Hegel sólo se atrevió a formular, lo que Marx pedía a la filosofía nueva: no quedarse sólo en el papel. No se trata de redimir a Genet, de recuperarlo sino al revés: Genet nos señala el camino, él puede redimirnos a nosotros porque su palabra no es palabra vacía, no es palabra de intelectual occidental académico bien acomodado. Sus textos son su vida, están escritos desde la experiencia sangrante de la vida. Genet ha arriesgado y por ello ha aprendido. Ha hecho de su vida su obra. No hay distancia entre su vida y su obra. Su palabra es su carne.

Con Genet Sartre busca dar una concreción a su propia filosofía, darle un contenido materialista y "carnal". Genet es la vida en su cruda desnudez. Genet es un cuerpo en carne viva. Un cuerpo expuesto a su entorno, un cuerpo que rechaza la seguridad académica y clasista. No hay distancia entre su vida y su obra. Por ello Sartre lo pone en el arranque de su nueva dirección filosófica, salida de la crisis del existencialismo. Porque Sartre entiende su propia "dialéctica" como una radicalización de su existencialismo, como su superación (Aufhebung). Sartre está pasando del existencialismo a la "razón dialéctica". Se hace marxista y freudiano, la misma combinación que llevarán a cabo los frankfurtianos para elaborar la "teoría crítica", 
cuyo texto fundante es La dialéctica de la Ilustración. Heidegger huye a la poesía desarraigada, porque "sólo un dios puede salvarnos", una fórmula que clausura la palabra. Muy lejos del camino de Sartre, que se hace Genet al escribir este texto. Es su espejo de escritor transgresor que no hace concesiones al lector. La brutalidad es un rasgo que a nadie se le oculta, pero es una brutalidad que se identifica con la vida. Se trata de un titánico ejercicio de sinceridad que deja la desnudez pornográfica a la intemperie, a la vista de todos, sin tapujos, sin reservas. Así el texto de Sartre sobre Genet ofrece una posibilidad de reconciliación con la parte oscura de la vida, con la muerte misma, con la naturaleza y celebra sus misterios órficos. "La Palabra se hizo carne y habitó entre nosotros" (Jn 1, 14), es el mensaje, ahora laico, el mensaje teológico del mismo Juan que Fichte hizo suyo aunque todavía sin ser capaz de despojar al mensaje de su ropaje abstracto, del imaginario religioso, que Hegel consiguió desvelar en su filosofía. Hegel entiende la sustancia como sujeto y, así, le da vida carnal; y Genet lo culmina. El "espíritu absoluto" no es otra cosa que la realidad hecha realidad viva, concreta, la que hace del tiempo su propio tiempo, la que hace de la vida su propia vida, la que hace de lo universal abstracto su universal concreto. La inmanencia de la vida, como diría Deleuze. Pero la inmanencia trascendente, no la inmanencia cerrada en sí misma. Este lenguaje es el que recupera lo religioso para la vida misma y, así, trasciende lo religioso como algo que se halla más allá de lo no-religioso, el que va más allá de la "conciencia infeliz", arqueologizando su contenido mismo, buscando su trasfondo. Sólo así lo infinito y lo finito se hacen uno, único. La vida misma en su inmanencia trascendente.

Sontag hace una crítica radical a la actual cultura americana, una crítica que va de la mano con la realizada por Adorno y Horkheimer. Sontag apunta dos autores esenciales de esta crítica: Marcuse (Eros y civilización,1955) y sobre todo Norman O. Browns (Life Against Death, 1959). Lo que les une a ambos es su crítica a las formas revisionistas de interpretación del psicoanálisis y su lectura materialista radical de Freud. Lo que Freud habría puesto sobre la mesa es la importancia del cuerpo. En él debemos centrar la atención, cosa que hace sin tapujos la pornografía. Pero más allá de Freud e incluso de Lacan, como subraya Zupančič, 2017, 128 ss: "One need to pursue it "beyond" Lacan, insofar as the organization of the psychoanalytic community is not usually considered to be Lacans strong point", ambos autores, Marcuse y Browns, subrayan la dimensión política de este descubrimiento. Las categorías psicoanalíticas son categorías políticas: una consecuencia que ni Freud (según Marcuse y Browns) ni Lacan (según Zupančič) habrían sabido llevar a sus últimas consecuencias. "Las implicaciones revolucionarias de la sexualidad en la sociedad actual se hallan muy lejos de ser bien entendidas." (dice Sonntag en su ensayo "Norman O. Browns Life Against Death and the psychoanalyse", que se ha- 
lla en el citado libro Against Interpretation). El psicoanálisis tal como se entiende y practica en América es el objeto de la crítica de Sontag: allí se entiende "como algo anti utópico y anti político, como un intento desesperado y en el fondo pesimista de proteger al individuo contra las exigencias ineludibles y las presiones de la sociedad". En la anteriormente citada entrevista (Die Zeit, Nr. 18 vom 23. April 1976) dice Sontag: "Die Phantasievorstellung einer sexuellen Apokalypse ist jedoch weit verbreitet - zweifellos ist sie ein Mittel zur Steigerung der sexuellen Lust. Und was uns das über den sozusagen inhumanen Charakter intensiver Lust mitteilt, wird von dem humanistischen "revisionistischen" Freudianismus ignoriert, der die unbändigen Kräfte der unbewußten oder irrationalen Gefühle minimalisiert und mit dem sich die meisten Feministinnen zufrieden geben." "La idea fantasmagórica de un apocalipsis sexual se halla muy difundida - sin duda se trata de un medio que eleva el deseo sexual. Y lo que nos indica sobre el llamado carácter inhumano del deseo intensivo, es ignorado por el freudianismo humanista "revisionista", el cual minimiza las fuerzas indomables de los sentimientos inconscientes o irracionales y con el cual la mayor parte de las feministas se dan por satisfechas").

Los intelectuales americanos se defienden contra el psicoanálisis como se habían defendido contra el marxismo. Ambos, psicoanálisis y marxismo, son los ingredientes básicos de los que se nutre el programa crítico. El psicoanálisis no es un método de tratar las neurosis como insatisfacciones individuales, sino un plan para transformar radicalmente la sociedad que provoca dichas neurosis. Sólo somos cuerpo, dice Browns, el núcleo de la neurosis humana consiste en el malestar en el cuerpo, y esto quiere decir de ser sexualmente. A nadie se le oculta que Freud mantuvo una ambivalente posición sobre la sociedad y la cultura, lo cual ha llevado a muchos de sus discípulos a posiciones conservadoras, revisionistas. Pero Freud podría haber hablado de "amor"; en cambio habló claramente de "sexualidad", lo cual apunta sin duda al cuerpo, a sus pulsiones, al componente material de estas fuerzas.

Sontag no duda en contrastar la tendencia que ella detecta en América, con la que se da en Francia. Como hemos visto anteriormente sus referencias son fundamentalmente de autores franceses. Lo cual podría ampliarse a otros ámbitos como el cine (Godart) o la pintura (Picasso). No es por tanto de extrañar que sean los franceses a los que podemos considerar los auténticos seguidores del programa crítico que se inició en Alemania (con Benjamin, Marcuse, Adorno o Horkheimer). Hoy en día Deleuze, Badiou, Derrida, ... son los herederos (naturalmente Sartre, Beauvoir, Lacan o Althusser prepararon el camino).

En España la cultura dominante controlada y manipulada por la Iglesia Católica se ha encargado de cerrar el paso a cualquier influencia "nociva" venida desde Francia fundamentalmente. Desde los llamados Reyes Católicos, España se cerró 
manu militari a cualquier heterodoxia ajena a la doctrina venida desde la autoridad católica. La Inquisición se encargó de perseguir cualquier desavenencia, real o sospechada, con dicha autoridad. Dentro y fuera de España (en los países recién "descubiertos"). Este régimen ha durado hasta el presente (con la notable excepción de dos Repúblicas que trataron de cambiar el decurso del país). Pero fue la llamada Generación del 98 la primera que se esforzó por confrontar la cultura española con la europea. Para ello tuvo que enfrentarse, entre otros, a los neocatólicos y también a los liberales (krausistas fundamentalmente) del siglo 19. Miguel de Unamuno y José Ortega y Gasset fueron figuras clave en este intento de modernizar España. Pero el franquismo supuso un varapalo a dichos intentos. Mientras Europa (fundamentalmente Francia y Alemania, cada uno a su manera) seguían su camino, España se iba quedando presa de su arrogante incultura. Kant, en su Antropología, hablando del carácter del pueblo español, escribe severamente: "er lernt nicht von Fremden, reiset nicht, um andere Völker kennen zu lernen; bleibt in Wissenschaften wohl Jahrhunderte zurück." ("No aprende de los extranjeros, no viaja para conocer otros pueblos; en las ciencias lleva siglos de retraso") ${ }^{1}$. El franquismo repuso la estrecha y rigurosa censura (que antes ya había sido abolida), fundamentalmente a la llamada cultura amoral y pornográfica que venía de Francia y, con ello, a cualquier modernización del país. La sexualidad sólo encontró su válvula de escape en infumables comedias y películas que plantean el sexo como objeto de burla e ironía machista, y en ningún caso suponen una confrontación seria con lo que sea la sexualidad. Incluso hoy en día sigue habiendo una gran reticencia con respecto a este tema. Los intelectuales oficiales actuales prefieren explotar sus bien pagados privilegios a enfrentarse seriamente a la renovación cultural profunda que exige la situación actual. Muchos de ellos se han vuelto a la derecha reaccionaria, dando la espalda a su programa inicial de elaborar una cultura crítica capaz de sacar a España del pozo en que su in-cultura delira. En 2016 apareció un libro valiente que ha pasado desapercibido. Su autor es Ignacio Sánchez Cuenca. En La desfachatez intelectual. Escritores e intelectuales ante la politica, su autor defiende que lo que llama "desfachatez intelectual" es un vicio muy extendido entre los intelectuales espańoles actuales. Estos intelectuales, escritores y hombres de letras en su mayoría, excelentes escritores muchos de ellos, se han hecho presentes en los debates políticos del país, pero con ideas superficiales y frívolas, expuestas en un tono insultantemente prepotente. En su mayoría fueron de izquierdas en su juventud y han ido asumiendo posiciones políticas conservadores hasta reaccionarias. Algunos de ellos no tienen ningún escrúpulo en aparecer

${ }^{1}$ I. Kant, Anthropologie in pragmatischer Hinsicht, Ak. VII, 316. J. M. Palacios, „La filosofía de Kant en la Espańa del siglo XIX", en o.c. 707. 
en mítines junto a los dirigentes del grupo político reaccionario VOX. El libro citado da abundantes ejemplos de ello. Los temas más candentes del momento como son el nacionalismo, el terrorismo o la crisis son tratados por estos intelectuales de modo poco crítico, incluso con una argumentación sin ningún fundamento, tanto desde el punto de vista de los hechos como de la lógica argumentativa misma, como defiende su autor con razón. En el fondo lo que falta en España, al contrario que en Alemania o en Francia, sería una verdadera cultura crítica, una cultura capaz de afrontar con autoridad la desfachatez con la que dichos intelectuales se atreven a vomitar su última ocurrencia en las bien pagadas columnas de los diarios o en tertulias televisivas. Un déficit democrático que es caldo de cultivo de los sofistas actuales. Lo que sorprende es que todos ellos son buenos conocedores de la cultura francesa, pero parecen no tener demasiado interés en difundirla en Espańa.

\section{Conclusión}

EN ESTUDIOS SOBRE LA HISTERIA, Freud y Breuer dan la clave del acceso al interior del ser humano. Esa clave es el lenguaje. Ni la hipnosis ni ningún otro medio es el instrumento adecuado para que el sujeto llegue a la "cosa". Pero no cualquier lenguaje. Es necesario que el sujeto acierte con el lenguaje que le permita reconstruir el camino perdido entre la palabra y la "cosa". Una vez reconstruido ese puente, alguna vez destruido, se puede recuperar el acceso a la "verdad" del problema. Cuando los pacientes son capaces de decir lo que les pasa, se acaba el problema, se restituye la "verdad". Esto quiere decir dos cosas. Primero, que la filosofía ha perdido la capacidad de establecer esta conexión con la "cosa" y que su trabajo es restituirla. Y, segundo, que el psicoanálisis, un psicoanálisis crítico, puede devolver a la filosofía su señal de identidad. Pues en él se puede lograr lo que la filosofía no es capaz de hacer.

La fuerza del lenguaje es la única fuerza capaz de llegar al fondo del alma humana. Tan es así que Lacan llega a decir, por ejemplo: "For the moment, I am not fucking, I am talking to you. Well! I can have exactly the same satisfaction as if I were fucking. That is what it means. Indeed, it raises the question of whether in fact I am not fucking at this moment." (Lacan, Seminars, Book XI)". En definitiva, el psicoanálisis desde el comienzo muestra el camino como una labor en el lenguaje mismo, es decir, como un camino filosófico. Pero es un camino filosófico con la condición que la filosofía misma se plantee como tarea crítica la restitución y recuperación de un lenguaje que abra el camino a los verdaderos problemas del sujeto, es decir, del mundo. Y estos conllevan un componente político que no se puede eludir. 
Cuando Sontag evoca al Hegel "post-religioso" (para nosotros post-pornográfico) está evocando la fuerza del lenguaje capaz de adentrarse tras la costra que cubre la superficie de lo empírico y llegar al corazón de lo que se esconde tras esa capa superficial. Los lenguajes a los que hace referencia Sontag (Sade, Bataille, Sartre, Genet, etc.) son formas de romper el hielo para adentrarse en las aguas submarinas ocultas tras él. El psicoanálisis es un fiel aliado en este trabajo.

Por post-pornográfico entendemos, en definitiva, un lenguaje que se adentre en las contradicciones sociales que afloran en una visión superficial de los contenidos y métodos pornográficos tan exitosos en nuestra sociedad. Este lenguaje tiene por tanto un contenido altamente político porque se inscribe en el corazón mismo de la sociedad pornográfica, desenmascarando la hipocresía que la intoxica y manipula. Para ello debemos mirar cara a cara, como propone Sontag, a dichos contenidos y no evitarlos o rechazarlos como moralmente detestables. Esta posición, extendida en ambientes puritanos, es acertadamente criticada por Sontag en varios de los artículos del libro suyo citado más arriba, Against Interpretation (1962).

Más allá del espacio conservador y burgués que impone un escenario único con una moral cínica (la pornografía es moralmente condenable pero muy rentable) es preciso construir escenarios nuevos, es preciso buscar lenguajes nuevos que abran nuevas posibilidades emancipatorias a los sujetos atrapados en incómodas cárceles ya insoportables por el alto nivel de sufrimiento y dolor que provocan. Es la tarea. Es preciso repensar también la pornografía, por tanto. Aquí filosofía, psicoanálisis, arte y política se encuentran a la búsqueda de una sociedad emancipada. Para ello es preciso elaborar un programa de acción común que traspase las barreras locales de cada disciplina.

El programa de la Teoría Crítica de Adorno y Horkheimer apunta en esta dirección. Marcuse es un sólido e imprescindible aliado. La mejor parte de la filosofía francesa actual (Lacan, Badiou, Deleuze, etc.) es impensable sin esta perspectiva. Ellos son los verdaderos herederos de aquella teoría. También quienes están elaborando actualmente sus posiciones a partir de ella, como Zizek o Butler, por citar quizás los más conocidos. Estos últimos elaboraron con Laclau en el año 2000 un programa que pretendía poner las bases para un nuevo punto de partida: Contingency, Hegemony, Universality: Contemporary Dialogues On The Left. Hay que seguir profundizando estas ideas.

Tienen razón quienes apuntan en la necesidad de volver a leer a Hegel. Hegel parte en su Fenomenología del sujeto tal como se halla en la modernidad, aislado frente a la todopoderosa sociedad capitalista que lo ahoga, y le va mostrando el camino hacia el Nosotros, el único camino posible. "Sólo el camino crítico es transitable", decía ya Kant. Hegel radicaliza esta intuición kantiana y la lleva hasta sus 
últimas consecuencias. El único camino posible es el que va del Yo al Nosotros. Y el Nosotros está inapelablemente anclado en lo que tenemos en común, en los cuerpos, en la sociedad, en la política, en la cultura, en definitiva, en la vida. Hacer posible este Nosotros es el reto. Incluso y, sobre todo, contra el sentido común neoliberal. 


\section{RefERenCias Bibliográficas}

Hegel (1807). Phänomenologie des Geistes. Felix meiner Verlag. 2014 Sontag, Susan (1967). „The Pornographic Imagination“, Partisan Review 34 (Spring 1967)

- Against Interpretation and Other Essays, New York: Farrar, Straus \& Giroux, 1966. Contra la interpretación, trad. Javier González-Pueyo, Barcelona: Seix Barral, 1969.

Sartre, Jean-Paul (1952). Saint Genet, Comédian et Martyr. Première parution en 1952. Nouvelle édition en 2011, Collection Tel ( $\left.\mathrm{n}^{\circ} 377\right)$, Gallimard.

Derrida, Jacques (1974). Glas. Editorial: Galilée, 1974. Trad. Clamor-glas. Oficina de arte y ediciones. 2015.

Réage, Pauline (pseudónimo de Dominique Aury) (1954). Histoire d'O, J.J. Pauvert, Sceaux, Hauts-de-Seine, 1954.

Zupančič, Alenka (2017). What is sex? Why sexuality is at the point of a "short circuit" between ontology and epistemology. Massachusetts Institute of Technology. The MIT edit.

Nabokov, Vladimir (1955). Lolita. Penguin. 1955.

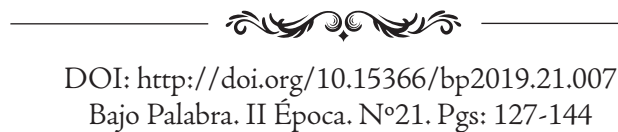

